\title{
ANAESTHESIA FOR PAEDIATRIC EYE SURGERY
}

ANAESTHESIA TUTORIAL OF THE WEEK 144

$27^{\text {TH }}$ JULY 2009

Dr. Grant Stuart, Great Ormond Street Hospital, London, UK Correspondence to grantstuart@imperial-anaesthesia.org.uk

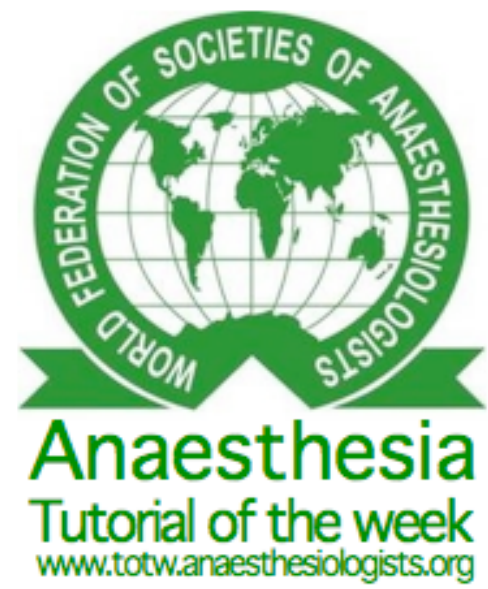

\section{SELF-ASSESSMENT QUESTIONS}

Please attempt the following true/false questions before starting the tutorial. The answers are displayed at the end of this tutorial.

$\begin{array}{ll}\text { Question 1 } & \text { The following ma } \\ \text { A } & \text { Ketamine } \\ \text { B } & \text { Sevoflurane } \\ \text { C } & \text { Suxamethonium } \\ \text { D } & \text { Propofol } \\ \text { E } & \text { Rocuronium } \\ \text { F } & \text { Hypocapnia } \\ \text { G } & \text { Coughing }\end{array}$

Question 2 The following is true about anaesthesia for Strabismus surgery:

A

Without the use of anti-emesis, it is associated with a $50-75 \%$ rate of post-operative nausea and vomiting (PONV).

B Patients are unlikely to exhibit the oculocardiac reflex.

C Males are more likely to have a squint than females.

D It is associated with a higher incidence of malignant hyperpyrexia.

E Patients may have occult myopathies.

Question 3 The oculocardiac reflex:

A Is mediated by the optic and vagus nerves

B $\quad$ May be reduced by administering $20 \mathrm{ug} / \mathrm{kg}$ of atropine intravenously (IV) at induction.

C Is most commonly induced by traction on the lateral rectus muscle.

D When present is associated with a higher incidence of PONV.

E Is more likely to occur when rocuronium is used rather than atracurium.

Question 4 The following is true about eye surgery for children:

A

Nitrous Oxide may be safely used in association with Sulphur

Hexafluoride in vitreoretinal surgery.

B Congenital glaucoma is usually unilateral.

C Congenital glaucoma is more common in female infants.

D Hereditary congenital cataracts are mostly inherited on an autosomal dominant basis.

E Cataracts are a major cause of morbidity in children, up to $85 \%$ occurring in Africa and Asia. 


\section{Introduction}

Unlike adults, children requiring eye surgery do not tolerate the use of sedation and local anaesthetic techniques and therefore almost always require general anaesthesia. This tutorial will present a general review of the principles of anaesthesia for children undergoing eye surgery and a description of anaesthesia for some specific procedures.

\section{General Principles of anaesthesia for Paediatric Eye Surgery}

\section{Preoperative considerations}

Most children presenting for eye surgery are healthy, ASA I or II and may be managed as day cases. A very small number may have underlying conditions, often of a chromosomal or metabolic nature, which pose more specific anaesthetic challenges $(1,2)$. Examples of these are described in the table below.

\begin{tabular}{|c|c|c|}
\hline Underlying condition & Eye condition & Special precautions \\
\hline Neonates (cataracts) & Congenital cataract & $\begin{array}{l}\text { As for neonatal surgery - warming, } \\
\text { glucose management, monitoring for } \\
\text { postoperative apnoea }\end{array}$ \\
\hline $\begin{array}{l}\text { Craniosynostosis syndromes } \\
\text { (Crouzons, Aperts, Pfeiffer) }\end{array}$ & $\begin{array}{l}\text { Glaucoma, cataracts, squint, } \\
\text { exopthalmos }\end{array}$ & $\begin{array}{l}\text { Difficult to maintain airway with } \\
\text { facemask (mid-face hypoplasia); } \\
\text { improved by Guedel airway; } \\
\text { intubation usually easy }\end{array}$ \\
\hline $\begin{array}{lr}\text { Craniofacial } & \text { syndromes } \\
\text { (Goldenhar, } & \text { Treacher } \\
\text { Collins, Smith-Lemli-Opitz) }\end{array}$ & Glaucoma, cataracts, squint & $\begin{array}{l}\text { Micrognathia/facial asymmetry } \\
\text { difficult intubation }\end{array}$ \\
\hline $\begin{array}{l}\text { Mucopolysaccharidoses } \\
\text { (Hunter and Hurler's } \\
\text { syndromes) }\end{array}$ & $\begin{array}{l}\text { Corneal opacities, retinitis } \\
\text { pigmentosa }\end{array}$ & $\begin{array}{l}\text { Difficult airway and intubation, } \\
\text { cardiomyopathy, } \\
\text { instability }\end{array}$ \\
\hline $\begin{array}{l}\text { Down's Syndrome, Edward's } \\
\text { Syndrome, Cri du Chat } \\
\text { syndrome }\end{array}$ & Cataracts, strabismus & $\begin{array}{l}\text { Difficult intubation, cervical spine } \\
\text { instability in Down's }\end{array}$ \\
\hline Hallerman-Strieff syndrome & Congenital cataract & Difficult intubation \\
\hline Stickler syndrome & $\begin{array}{l}\text { Glaucoma, } \begin{array}{r}\text { Chorioretinoid } \\
\text { degeneration, lens dislocation }\end{array} \\
\end{array}$ & $\begin{array}{l}\text { Cleft palate and associated airway } \\
\text { problems }\end{array}$ \\
\hline Homocystinuria & Lens disclocation & Hypoglycaemia \\
\hline Marfans's syndrome & Lens dislocation & $\begin{array}{l}\text { Aortic root dilatation, aortic/mitral } \\
\text { valve regurgitation }\end{array}$ \\
\hline $\begin{array}{l}\text { Neuro-oculo-cutaneous } \\
\text { disorders (Neurofibromatosis } \\
\text { Sturge Weber syndrome, } \\
\text { tuberous sclerosis, Von- } \\
\text { Hippel-Lindau syndrome }\end{array}$ & Retinal vascular disorders & $\begin{array}{l}\text { Seizures, intracranial lesions, cardiac } \\
\text { lesions and phaeochromocytoma }\end{array}$ \\
\hline
\end{tabular}

\section{Ophthalmic medications}

Many children requiring eye surgery will be taking or will subsequently receive eye drops. A basic knowledge of commonly used preparations and their potential effects is useful. There is a theoretical risk that these medications could be absorbed through the pharyngeal mucosa via the nasolacrimal ducts, causing systemic effects, although it is unusual that this causes a significant problem $(2,3,4)$. 


\begin{tabular}{|c|c|c|}
\hline Eye preparations & Indication & Systemic side effect \\
\hline $\begin{array}{l}\text { Beta-blockers: } \\
\text { Timolol maleate or Betaxolol } \\
\text { hydrochloride) }\end{array}$ & Glaucoma & $\begin{array}{lcc}\text { Bradycardia } & \text { refractory } & \text { to } \\
\text { atropine; bronchospasm } & \text { in } \\
\text { asthmatics } & & \\
\end{array}$ \\
\hline $\begin{array}{l}\text { Carbonic anhydrase inhibitors: } \\
\text { Acetazolamide (diamox) }\end{array}$ & Glaucoma & $\begin{array}{l}\text { Metabolic acidosis, electrolyte } \\
\text { abnormalities, } \\
\text { including allergies, } \\
\text { syndrome }\end{array}$ \\
\hline $\begin{array}{l}\text { Antimuscarinic agents: } \\
\text { Cyclopentolate or Atropine }\end{array}$ & Pupil dilatation & $\begin{array}{l}\text { Dry mucous membranes, nausea } \\
\text { and vomiting, tachycardia }\end{array}$ \\
\hline $\begin{array}{l}\text { Alpha-adrenergic } \\
\text { sympathomimetic agents: } \\
\text { 9Phenylephrine } 2.5 \% \text { ) }\end{array}$ & Pupil dilatation & Hypertension, tachycardia \\
\hline $\begin{array}{l}\text { NSAIDS: } \\
\text { Diclofenac sodium, Ketorolac } \\
\text { trometamol } 0.5 \%\end{array}$ & Pain relief & $\begin{array}{l}\text { Potential to worsen } \\
\text { precipitate acute asthma }\end{array}$ \\
\hline $\begin{array}{l}\text { Local anaesthetic agents: } \\
\text { Amethocaine (Tetracaine), } \\
\text { Oxybuprocaine, Proxymetacaine }\end{array}$ & Pain relief or prevention & $\begin{array}{l}\text { Local anaesthetic toxicity, } \\
\text { particularly preterm neonates }\end{array}$ \\
\hline
\end{tabular}

\section{Anaesthetic considerations}

\section{Pre-medication, induction of anaesthesia}

The decision to pre-medicate the child and the choice of induction technique (intravenous or inhalational) should be tailored both to the needs of the child and to the preferences of the anaesthetist. It should be remembered that where the child has poor vision, they should be approached and handled in a careful and sensitive manner.

\section{Airway management}

Airway management should be tailored to the procedure. For measurement of intraocular pressure (IOP), maintenance of spontaneous respiration via a facemask should be used, as intubation will raise the intraocular pressure. For simple procedures such as examination under anaesthesia (EUA) some anaesthetists might find it more convenient to maintain spontaneous respiration through a reinforced laryngeal mask airway (LMA), particularly where a sterile field is required.

The reinforced LMA may be used in older children for most eye procedures. It has the advantages of reduced coughing at the end of the surgery and controlled ventilation with the use of muscle relaxants is possible.

Intraocular surgery requires a still eye with low intraocular pressure and the airway is best managed by intubation with paralysis and controlled ventilation. Similarly, eye surgery in very young children is best managed with intubation and controlled ventilation to ensure a secure airway. Access to the airway will be restricted during the surgery so it is important to secure the tracheal tube firmly. A preformed south facing RAE tube is ideal, but this may be too long in neonates; a reinforced flexible tracheal tube (ETT) may be preferable in this situation.

\section{Maintenance of anaesthesia}

As with induction, the choice of maintenance technique rests largely on the preferences of the anaesthetist and the availability of different agents.

Where halothane is used there is an increased risk of dysrhythmias, particularly where eye preparations containing atropine or adrenaline are used, and in the presence of hypercapnia. Isoflurane or sevoflurane may be preferable. 
Total intravenous anaesthesia (TIVA) with propofol has advantages in reducing the risk of postoperative nausea and vomiting (PONV) since propofol has anti-emetic effects. Remifentanil can reduce volatile requirements $(5,6)$.

The use of nitrous oxide in eye surgery is limited by two factors. Firstly nitrous oxide is known to increase the risk of PONV, and in ophthalmic procedures there is a high incidence of PONV, so most anaesthetists will tend to avoid its use. Secondly, nitrous oxide diffuses from the blood into gas filled spaces in the body. It should be avoided in vitreoretinal detachment surgery where intraocular gas bubbles of sulphur hexachloride or perfluropropane are introduced into the eye to tamponade detached surfaces. If nitrous oxide is used for a patient who has had recent vitreoretinal surgery (the bubble may last several weeks), or if it is commenced mid procedure, it can cause a significant rise in intraocular pressure with resultant ischaemic damage. Alternatively, if nitrous oxide was used from the start of the anaesthetic, prior to placement of the gas bubble, it will diffuse out of the bubble on completion of the anaesthetic, and the bubble will shrink and risk re-detachment.

\section{Anaesthetic agents and intraocular pressure}

Normal intraocular pressure (IOP) ranges from $10-20 \mathrm{mmHg}$. Most anaesthetic agents will decrease this. The table below describes the effects of commonly used anaesthetic agents on IOP. If serial measurements of IOP are being made, it is important to be consistent with the type of anaesthetic used on different occasions (see below) (1,2,7-12).

\begin{tabular}{|l|l|}
\hline Anaesthetic agent & Effect on intraocular pressure \\
\hline Propofol, thiopentone & IOP reduced by $20-30 \%(3-7 \mathrm{mmHg})$ \\
\hline Halothane, sevoflurane, isoflurane, desflurane & IOP reduced by $20-30 \%(3-7 \mathrm{mmHg})$ \\
\hline Opioids & Minimal to no effect on IOP \\
\hline Ketamine & $\begin{array}{l}\text { Minor dose dependent increase in IOP; marked } \\
\text { effect when dose exceeds } 5 \mathrm{mg} / \mathrm{kg}\end{array}$ \\
\hline Atropine & No effect on IOP \\
\hline Non-depolarising muscle relaxants & Minimal to no effect on IOP \\
\hline Suxamethonium & $\begin{array}{l}\text { Significant increase in IOP within 30secs of } \\
\text { administration (approx 8mmHg), effect lasts for } \\
5-7 \text { minutes, less if given with agents that reduce } \\
\text { IOP }\end{array}$ \\
\hline Acetazolamide, mannitol, dextrans & Used for acute reduction of IOP perioperatively \\
\hline
\end{tabular}

\section{Anaesthetic techniques and intraocular pressure}

Physical and physiological variables have an important effect on IOP.

Laryngoscopy, coughing, straining, crying, bucking and the process of tracheal extubation may all cause a rise in IOP. This effect may be attenuated by a dose of lidocaine $1 \mathrm{mg} / \mathrm{kg} 3$ minutes prior to intubation or extubation. Use of the LMA allows smoother induction and emergence from anaesthesia and has much less effect on IOP $(13,14,15)$.

Hypoxia and hypercapnia both increase IOP.

Hypocapnia and hypothermia decrease IOP.

\section{The Oculocardiac Reflex}

The oculocardiac reflex is frequently encountered during eye surgery in children and is seen in up to $60 \%$ of children undergoing strabismus surgery. It is therefore essential to use continuous heart rate monitoring with an ECG during eye surgery in children. The reflex takes its afferent innervations from the ophthalmic division of the trigeminal nerve, relays via the sensory nucleus in the $4^{\text {th }}$ ventricle, with the efferent impulse in the vagus nerve $(1,2)$. 
Surgical traction on the extra-ocular eye muscles or pressure on the globe causes a sinus bradycardia, and occasionally junctional rhythms, atrioventricular block, atrial ectopics or ventricular ectopics. The reflex is most commonly induced by traction on the medial rectus muscle, rather than the smaller lateral rectus muscle. The bradycardia resolves almost immediately after the stimulus has been removed and weakens with repetition of the stimulus.

Intravenous atropine $20 \mathrm{mcg} / \mathrm{kg}$ or glycopyrrolate $10 \mathrm{mcg} / \mathrm{kg}$ at induction of anaesthesia will block the oculocardiac reflex. If not given at induction, it is important to have the drugs drawn up and ready to administer if bradycardia should occur.

The reflex may be attenuated by application of topical local anaesthetic agents to the eye (such as tetracaine eye drops), or by blocking the afferent limb of the reflex with a peribulbar block, although this block is not usually used in children due to the risk of globe perforation $(16,17)$.

Sevoflurane is less likely to provoke the reflex than halothane, it is also less likely with deep anaesthesia compared to light anaesthesia. The incidence of significant bradycardia is doubled if the carbon dioxide level is high, so controlled ventilation should be considered. The oculocardiac reflex is more likely to occur with rocuronium rather than atracurium $(1,19)$.

Children who exhibit the oculocardiac reflex are more likely to develop PONV (18) and should receive an antiemetic during anaesthesia.

\section{Extubation and emergence from anaesthesia}

It is important to avoid coughing and bucking on the tracheal tube at the end of surgery, particularly for those children who have undergone intraocular surgery. For this reason, many anaesthetists use a laryngeal mask airway for eye surgery for suitable patients. If the patient has been intubated, deep extubation has been the method of choice, but this is contraindicated for emergency surgery (full stomach) or those in whom the airway management is difficult. These children can be extubated awake with a dose of lidocaine $1 \mathrm{mg} / \mathrm{kg}$ IV to reduce the effects of extubation on IOP.

\section{Principles of pain relief and postoperative care}

Most eye or orbital procedures result in only mild to moderate postoperative pain. This is well managed with simple analgesics such as paracetamol, NSAIDS and topical local anaesthetic agents. These may be given pre-emptively as oral preparations preoperatively or rectally/IV at induction.

Squints, evisceration and vitreoretinal surgery cause more severe pain requiring stronger analgesia. Intraoperative analgesia should include paracetamol, a NSAID, intravenous fentanyl and topical local anaesthetic if possible. Multimodal analgesia should be continued into the postoperative period, with the addition of codeine phosphate or tramadol, escalating to morphine if required. The use of opioids increases the risk of PONV and antiemetics are essential.

PONV is extremely common after paediatric eye surgery, and for strabismus surgery can be as high as $60 \%$ if no prophylaxis is given. A dose of ondansetron $0.15 \mathrm{mg} / \mathrm{kg}$ has been shown to significantly reduce PONV, and combination therapy (ondansetron and dexamethasone $0.1-0.2 \mathrm{mg} / \mathrm{kg}$ ) goes even further, reducing PONV to as low as $10 \%$ in strabismus surgery. It is wise to leave the IV cannula in place postoperatively where PONV may be a problem so that further anti-emetics and IV fluids might be given $(20,21,22)$.

Where ketamine has been given, the likelihood of emergence phenomena should be considered and the child should be recovered in a quiet area with minimal stimulation (12).

Most paediatric eye procedures are treated as day cases and children can resume oral intake as early as they feel like. Occasionally the high incidence of PONV results in an unplanned overnight admission. 


\section{ANAESTHESIA FOR SPECIFIC OPHTHALMIC CONDITIONS AND PROCEDURES}

\section{EUA and measurement of IOP}

For an examination of the eyes under anaesthesia, either an inhalational or intravenous induction technique and airway maintenance with a facemask will suffice. It may be technically easier to place an LMA for a longer EUA.

For measurement of IOP, it should be remembered that most anaesthetic agents decrease IOP, and this can potentially mask a high IOP and compromise care.

Some anaesthetists advocate the use of ketamine as it does not drop IOP, and although it may slightly raise IOP, this may be safer than having a falsely low reading. Ketamine is given as $1-2 \mathrm{mg} / \mathrm{kg} \mathrm{IV}$, or where there is no IV access available, as $5-10 \mathrm{mg} / \mathrm{kg}$ IM. Ketamine increases secretions so must always be given with either atropine $20 \mathrm{mcg} / \mathrm{kg}$ IV or glycopyrolate $10 \mathrm{mcg} / \mathrm{kg} \mathrm{IV}$. It is essential to maintain an open airway, but instrumentation of the airway is rarely required $(1,11,12)$.

An acceptable alternative technique to ketamine is to use inhalational induction with sevoflurane with the ophthalmologist present, and to measure the IOP as soon as the child is still. The sevoflurane should be kept at $<5 \%$, the child's eyes should be central and the facemask must not press on the eyes. Regardless of the technique used, the IOP should always be measured before laryngoscopy or LMA insertion, although there is little evidence to prove that the latter significantly raises IOP. A consistent technique should be ensured if serial measurements of IOP are to be made.

\section{Syringing and probing of nasolacrimal ducts}

Children with blocked nasolacrimal ducts will usually present early in life with increased tearing from their eyes. They will require probing of their nasolacrimal ducts, a short procedure for which an LMA will suffice.

Should simple probing fail, the surgeon might place a silicone catheter through the duct where it is secured for a few weeks. Alternatively the inferior turbinate bone may be fractured to relieve the obstruction.

Dacrocystorhinostomy is a more extensive procedure that involves exposure of the duct and creation of a new opening into the nasal cavity (1)

Anaesthetic considerations:

- The surgical team may require placement of a topical vasoconstrictor onto the child's nasal mucosa.

- Hypotensive anaesthesia may be required to reduce bleeding.

- The airway should be protected from blood, ideally with a throat pack, and the nasopharynx should be adequately suctioned out before extubation.

- Opioids may be required for analgesia for this procedure.

- The use of antimicrobial prophylaxis for those at risk of infective endocarditis is no longer routinely recommended for this procedure.

\section{Strabismus surgery}

Squint is a common problem that affects $3-5 \%$ of the population, making strabismus surgery the most commonly performed paediatric eye surgery. It affects males and females equally.

Squints are usually idiopathic, but may also be secondary to intracerebral space occupying lesions, trauma, infection or inflammation causing muscle palsies. Most patients are healthy, but occasionally squints may be associated with a family history, prematurity, and disorders of the central nervous system such as cerebral palsy, hydrocephalus and myelomeningocoele. Patients may have occult 
myopathies and there is a threefold increase in the incidence of masseter spasm. Although unproven, there is anecdotal evidence of an increased association with malignant hyperpyrexia (2).

Squint correction is achieved by lengthening (recession), shortening or tightening (resection) or transposition of any of the four rectus and two oblique extra-ocular muscles, or combinations of any of the above.

Surgeons may use forced duction testing to distinguish a paretic muscle from one that has restricted motion. In minor strabismus surgery, botulinum toxin may be injected into the extra-ocular muscle requiring electromyelogram (EMG) control. In these cases muscle relaxants should be avoided (1).

In older children an adjustable suture may be used that allows fine adjustments to be made $24-48$ hours postoperatively under topical local anaesthetic once the patient is awake.

Anaesthetic considerations:

- Induction technique, method of airway control and choice of ventilation according to the preference of the anaesthetist.

- Maintenance of anaesthesia is usually achieved with a volatile anaesthetic agent and air; the use of total intravenous anaesthesia (TIVA) has been shown to reduce PONV.

- Consider atropine $20 \mathrm{mcg} / \mathrm{kg}$ IV or glycopyrolate $10 \mathrm{mcg} / \mathrm{kg}$ IV as high incidence of oculocardiac reflex.

- $\quad$ PONV is common postoperatively, up to $50-75 \%$. Giving two anti-emetic agents such as ondansetron $0.1 \mathrm{mg} / \mathrm{kg}$ IV and dexamethasone $0.1-0.2 \mathrm{mg} / \mathrm{kg}$ IV can reduce this to $10 \%$. $(20,21,22)$.

- Ideally extubate the child deeply.

- Analgesia should include topical tetracaine or oxybuprocaine, NSAIDS such as ibuprofen or diclofenac and paracetamol, unless contraindicated.

- Intraoperative opioids should be avoided due to the high incidence of PONV, but where necessary, consider the use of fentanyl.

- A peribulbar block is effective for analgesic requirements and reduces PONV, possibly by blocking the ophthalmic division of the trigeminal nerve that passes to the vomiting centre in the medulla. The risk of globe perforation in children makes most practitioners cautious of this (17).

- A sub-Tenon block performed intraoperatively by the surgeon can be very effective for analgesia.

\section{Glaucoma}

The pressure within the eye is maintained through a balance between the production of aqueous humor, primarily by the ciliary body in the posterior chamber, and drainage via the trabecular network to the canal of Schlem in the anterior chamber.

In glaucoma the normal IOP of $10-20 \mathrm{mmHg}$ becomes elevated such that capillary blood flow to the optic nerve becomes reduced, compromising the function of the optic nerve. The causes of glaucoma are varied.

- Primary Congenital glaucoma is caused by a failure of the development of the trabecular network, reducing the drainage of aqueous humour. It is bilateral in $75 \%$ of cases and has a prevalence of 1:10000 births. There is a male to female ratio of $35 \%: 65 \%$ and it is seen more commonly in children below the age of 3 years.

- Secondary Glaucoma is usually caused by a blockage of existing drainage channels and this can be caused by infection, inflammation or trauma. It is also seen in some rare syndromes such as Sturge - Weber Syndrome, Axenfeld Syndrome and in association with aniridia in $20 \%$ of patients with Wilm's tumour (2).

Treatment may be medical or surgical. Medical treatment consists of drugs used to reduce IOP such as acetazolamide $15-30 \mathrm{mg} / \mathrm{kg}$ /day in $3-4$ divided doses, which suppresses aqueous production. Its 
usefulness is limited since the causes of glaucoma are usually structural and related to drainage. After EUA and measurement of IOP, surgical treatments may vary.

- Goniotomy involves visualising the anterior chamber with a gonioscope and making an incision into the trabecular meshwork to allow drainage.

- Trabeculotomy involves the insertion of a fine probe into Schlem's canal to create a new drainage channel.

- Trabeculectomy involves the creation of a new drainage channel from the anterior chamber into sub-Tenon's space where the aqueous is absorbed.

- Cyclocryotherapy is the ablation of part of the ciliary body by a cryoprobe at ${ }^{-} 60$ to ${ }^{-} 80{ }^{\circ} \mathrm{C}$ to reduce the production of aqueous humour (2).

Anaesthetic considerations:

- $\quad$ Avoid raising the IOP by ensuring a smooth induction and deep emergence without coughing.

- Maintain a motionless eye; consider paralysis and controlled ventilation to avoid hypercapnia.

- Analgesia with paracetamol and NSAIDS is usually adequate, however when cyclocryotherapy is used opioids may be necessary.

- High incidence of PONV - routine anti-emetics.

\section{Cataract extraction}

Cataracts are a major cause of childhood morbidity worldwide, predominantly in the developing countries in Africa and Asia (85\% of cases).

Aetiology may be varied (2):

- Hereditary cataracts are usually inherited via autosomal dominant patterns and present in otherwise healthy children.

- Syndromes may be associated with cataracts. Some include Lowe's oculo-cerebro-renal syndrome (X-linked recessive), Down's syndrome (Trisomy 21), Edward's Syndrome and Cri-du-chat syndrome.

- Metabolic causes may include Glucose-6-phosphate dehydrogenase deficiency, hypoglycaemia, hypocalcaemia and galactosaemia.

- Blunt or penetrating trauma usually results in unilateral cataracts.

- Inflamation such as the uveitis associated with Juvenile chronic arthritis may cause cataracts.

- Tumours, such as retinoblastoma.

- Intrauterine infections, including Rubella, Cytomegalovirus (CMV), Toxoplasma and Toxocariasis.

- $\quad$ Radiation for leukaemia might cause cataracts.

- Chronic steroid use

Treatment involves surgical implantation of an intraocular lens, which may need to be done very early (as early as 4 weeks old) in order to allow stimulation of the retina and visual development. The procedure takes about 30 - 60 minutes, but complications can be more frequent than in adults and include uveitis, glaucoma, endophthalmitis, iris damage or prolapse, retinal detachment and thickening of the posterior lens capsule (2).

Anaesthetic considerations:

- Aim for a motionless eye either with deep anaesthesia or a paralysed patient.

- Avoid high IOP with a smooth induction and emergence.

- Consider controlled ventilation to avoid hypercapnia.

- Give anti-emetics.

\section{Enucleation and evisceration}

Enucleation is the removal of the whole eye. This may be done for surgical treatment of a retinoblastoma, significant eye trauma or for cosmetic reasons where an eye is blind. It involves the dissection of the extra-ocular muscles off the globe. Anaesthetists should be aware that there is similar 
risk here for the oculocardiac reflex, although less risk of PONV, and should manage the case as for strabismus surgery.

Evisceration involves the removal of the contents of the globe, but retention of the sclera. This procedure is often painful and opioid use should be considered (1).

\section{Penetrating eye surgery}

A penetrating injury to the eye is a relatively common injury in children, primarily boys between 3 and 9 years, and requires surgery to close the defect or remove a foreign body. Surgery is urgent as anything that raises IOP (coughing, straining) may cause the globe to extrude its contents $(2,3)$.

This presents two conflicting anaesthetic problems. Firstly, the child may have a full stomach so a rapid sequence intubation with suxamethonium is indicated in order to prevent aspiration. Secondly there is a need to protect the globe from a rise in IOP that could result in extrusion of the structures of the anterior chamber or the vitreous humor. The transient rise in intraocular pressure produced by the use of suxamethonium could theoretically cause this (23).

- One approach recommends the use of a large dose of non-depolarising muscle relaxant (NDMR) and ventilation with cricoid pressure until intubating condition is achieved, providing the child has a normal airway (10).

- Another view is that there have been no documented reports of vitreous extrusion after the use of suxamethonium, and protection of the airway is paramount (24); hence the use of suxamethonium and a traditional rapid sequence induction is indicated.

- The advent of suggamadex a drug that can rapidly reverse rocuronium (rapid onset, long acting muscle relaxant) may allow rapid sequence induction using rocuronium to be used as an alternative technique in the presence of a more challenging airway.

Other considerations include:

- Crying, coughing and straining should be avoided; consider light oral sedation and analgesia preoperatively.

- Direct larygnoscopy of a poorly paralysed airway can cause coughing and bucking, whichever technique is used.

- Consider blunting the intubation response prior to laryngoscopy. Administer lidocaine $1-2$ $\mathrm{mg} / \mathrm{kg}$ IV given 3 minutes prior to rapid sequence intubation during preoxygenation

- Consider monitoring the child with a nerve stimulator after adminstration of the muscle relaxant.

\section{Vitreoretinal surgery}

Vitreoretinal surgery is performed for the repair of a detached retina, and although unusual, may be necessary in children. Detachment may be primary where it is related to a defect in the retina, or secondary to an underlying illness. The surgery involves creating a choreoretinal scar with cryotherapy and placing a scleral buckle towards the back of the eye, which serves to oppose the neuroretina and retinal pigment epithelium. The surgeon may also place an intraocular bubble of either sulphur hexafluoride or perfluropropane to tamponade the detached surfaces together $(1,2)$.

Anaesthetic considerations:

- Avoid nitrous oxide if an intraocular gas bubble is used.

- Avoid nitrous oxide in patients who have had an intraocular bubble placed for several weeks after the procedure. Parents should be given clear instructions in this regard for future anaesthetics.

- Controlled ventilation and paralysis should be considered for maintaining a still eye and avoiding raised IOP during the procedure.

- This procedure is painful and analgesia including opioids should be considered.

- Anti-emesis should be used routinely

- Avoid raised IOP during extubation - extubate deep. 


\section{CONCLUSION}

This tutorial has reviewed the general principles of anaesthesia for paediatric eye surgery, as well as considerations for some common procedures. Key learning points include:

- Children require general anaesthesia for ophthalmic procedures and surgery, but most are healthy and can be managed as day cases.

- The oculocardiac reflex may be induced during eye surgery and risks produce dangerous bradycardias, which can be prevented by premedicating with anticholinergic agents.

- Post operative nausea and vomiting is common after eye surgery in children and might delay discharge if suitable prophylaxis is not given.

\section{SELF-ASSESSMENT ANSWERS}

\section{Question 1}

A $\mathrm{T}$

B $\quad \mathrm{F}$

C $\mathrm{T}$

D F

E F

F F

G $\quad \mathrm{T}$

\begin{tabular}{lc}
\multicolumn{2}{l}{ Question 2 } \\
A & T \\
B & F \\
C & F \\
D & T \\
E & T
\end{tabular}

$\begin{array}{cc}\text { Question 3 } \\ \text { A } & \text { F } \\ \text { B } & \text { T } \\ \text { C } & \text { F } \\ \text { D } & \text { T } \\ \text { E } & \text { T }\end{array}$

\section{Question 4}

A $\mathrm{F}$

B $\mathrm{F}$

C $\mathrm{T}$

D $\mathrm{T}$

E $\mathrm{T}$

\section{REFERENCES}

1. James I, Anaesthesia for paediatric eye surgery. Continuing Education in Anaesthesia, Critical Care and Pain 2008 8: 5 - 10

2. Morrison A, Ophthalmology, plastics, oncology, radiology, thoracic, and dental surgery. In: Doyle E, eds. Paediatric Anaesthesia. Oxford, Oxford University Press. 2007; 298 - 307.

3. Steward DJ, Lerman J. Manual of Pediatric Anesthesia. Churchill Livingstone, 2001; 225 233.

4. BNF for children. Notes on drugs and preparations: Eye. BMJ group, RPS Publishing. 2008, $606-627$.

5. Reimer EJ, Montgomery CJ, JC Bevan, et al. Propofol anaesthesia reduces early postoperative emesis after paediatric strabismus surgery. Canadian Journal of Anaesthesia. 1993; 40: 927 933.

6. Marsh DF, Hodkinson B. Remifentanil in paediatric anaesthetic practice. Anaesthesia. 2009 64: $301-308$.

7. Sator S, Wilding E, Schabering C, et al. Desflurane maintains intraocular pressure at an equivalent level to isoflurane and propofol during unstressed non-ophthalmic surgery, British Journal of Anaesthesia. 1998; 80: 243 -245.

8. Sator - Katzenschlager S, Deusch E, Dolezal S, et al. Sevoflurane and propofol decrease intraocular pressure equally during non-ophthalmic surgery and recovery. British Journal of Anaesthesia. 2002; 89: 764 - 767.

9. Sator-Katzenschlager SM, Oehmke MJ, Deusch E, et al. Effects of remifentanil and fentanyl on intraocular pressure during the maintenance and recovery of anaesthesia in patients undergoing non-ophthalmic surgery. European Journal of Anaesthesiology. 2004; 21: 95 101.

10. Chiu CL, Jaais F, Wang CY, Effect of Rocuronium compared with succinylcholine on intraocular pressure during rapid sequence induction of anaesthesia. British Journal of anaesthesia. 1999, 82: 757 - 761. 
11. Craven R. Ketamine. Anaesthesia. 2007; 62: 48 - 53.

12. Pun MS, Thakur J, Poudyal G, et al. Ketamine anaesthesia for paediatric ophthalmology surgery. British Journal of Ophthalmology. 2002; 87: 535 - 538.

13. Lerman J, Kiskis AA. Lidocaine attenuates the intraocular pressure response to rapid intubation in children. Canadian Anaesthetists' Society Journal. 1985; 32: 339 - 345.

14. Drenger B, Pe'er J. Attenuation of the ocular and systemic responses to tracheal intubation by intravenous lignocaine. British Journal of Ophthalmology. 1987; 71: 546 - 548.

15. Gulati M, Mohta M, Ahuja S, et al. Comparison of Laryngeal Mask Airway with tracheal Tube for Ophthalmic Surgery in Paediatric patients. Anaesthesia and Intensive Care. 2004; 32: $383-390$.

16. Ruta U, Mollhoff T, Markodimitrakis H, Brodner G. Attenuation of the oculocardiac reflex after topically applied lignocaine during surgery for strabismus in children. European Journal of Anaesthesiology. 1996; 13: $11-15$.

17. Gupta N, Kumar R, Kumar S, et al. A prospective randomised double blind study to evaluate the effect of peribulbar block or topical application of local anaesthesia combined with general anaesthesia on intra-operative and postoperative complications during paediatric strabismus surgery. Anaesthesia. 2007 62: $1110-1113$.

18. Allen LE, Sudesh S, Sandramouli S, Cooper G, et al. The association between the oculocardiac reflex and postoperative vomiting in children undergoing strabismus surgery. Eye. 1998; 12: 193 - 196.

19. Yi C, Jee D. Influence of the anaesthetic depth on the inhibition of the oculocardiac reflex during sevoflurane anaesthesia for paediatric strabismus surgery. British Journal of Anaesthesia. 2008; 101: $234-234$.

20. Rose JB, Martin TM, Corddry DH, et al. Ondansetron reduces the incidence and severity of post strabismus repair vomiting in children. Anaesthesia and Analgesia. 1994; 79: 486 - 489.

21. Sennaraj B, Shende D, Sadhasivam S, et al. Management of post-strabismus nausea and vomiting in children using ondansetron: a value-based comparison of outcomes. British Journal of Anaesthesia. 2002; 89: 473 - 478.

22. Tramer M, Moore A, McQuay H. Prevention of vomiting after paediatric strabismus surgery: a systematic review using numbers-needed-to-treat method. British Journal of Anaesthesia. 1995; 75: $556-561$.

23. Murphy DF, Anaesthesia and Intraocular pressure. Anaesthesia and Analgesia. 1985; 64: 520 -530 .

24. Vachon CA, Warner DO, Bacon DR. Succinylcholine and the open globe: tracing the teaching. Anaesthesiology. 2003; 99: $220-223$. 